\title{
Intravenous piggyback infusion control and monitoring system using wireless technology
}

\author{
Gil R. delas Alas Jr*, Jesusa N. Padilla and Bartolome T. Tanguilig III \\ Graduate Programs, Technological Institute of the Philippines, Quezon City, Philippines
}

\section{(C)2016 ACCENTS}

\begin{abstract}
Intravenous infusion is one of the most common treatments administered to patients. However, there are patients who undergo surgery, patients who are in a state of coma, and patients with dengue cases to name a few. This patient requires continuous medication and this treatment is called piggyback infusion. In such cases, continuous monitoring is an indispensable factor in patient care. Efficient monitoring and controlling can be made possible by using wireless control for the device. This paper is about a microcontroller-based intravenous piggyback infusion system that will monitor and control using Wireless Sensor Network (WSN). This paper also discusses remote wireless Ethernet-based communication which can monitor and control the infusion rate by using PC and Android mobile phone. This also discusses the implementation of an infrared sensor installed in the drip chamber of the intravenous infusion (IV) set which is capable of counting the drop rate in real time monitoring.
\end{abstract}

\section{Keywords}

Control system, Intravenous infusion, Piggyback infusion, WSN, The peristaltic pump.

\section{Introduction}

Hospitals use the intravenous infusion therapy to treat patients. This infusion therapy uses a fluid or a solution that is directly administered into the patient's vein. This infusion therapy provides nutrition for a patient who does not have the capability to take food through their mouth. It is also used to restore their lost fluid [1]. Some patients who require infusion therapy are those who are undergoing the surgical operation and those who are in a comatose condition to name a few. Some of the advantages of the said medication are the following: 1 . it delivers parental and nutritional supplements, and 2. it restores and maintains fluid and electrolyte balance [1][2]. The infusion can be calculated by the simple formula as shown in (1): [3][4][16][20][21]

Drop rate per minute $(\mathrm{Dpm})$

$$
\frac{\text { Volume to be infused }(\mathrm{ml})}{\text { Time for Infusion }(\mathrm{hr})} \times \frac{1}{\text { Drop Size }} \times \frac{1 \mathrm{hr}}{60 \mathrm{~min}}
$$

In some cases, intravenous infusion is given continuously depending on the condition of the patient and to doctor's order.

*Author for correspondence
This continuous infusion is called an intermittent infusion or piggyback infusion, which being implemented if a patient is receiving a continuous medication. Intravenous infusion is a medical term that describes the way certain kinds of medicines or other substances delivered to the body. In 2009, as stated by Dr. Dimaano, a biomedical expert and head of San Lazaro Hospital Medical Division Philippines, in his interview on a Philippine TV network, that mild dengue patients admitted in hospitals are given intravenous fluid, which remains the foundation of dengue management in the country. Dr. Dimaano also added that this fluid overload or pulmonary congestion is recognized as the most common cause of death in dengue cases [5].

But the infusion of intravenous fluid should be judiciously observed in such cases since mild dengue patients recover more quickly and have lower haematocrit levels than those with severe cases. The unmonitored intravenous therapy could lead to fluid overload or pulmonary congestion, which could kill a patient. The intravenous infusion process requires a real-time monitoring based on the patient's condition and the drug requirements. But in the Philippine hospital setting, some of the medical practitioners are still using the manual process of monitoring and controlling the intravenous infusion process. In such 
process, the medical practitioner will consume a lot of time to constantly monitor and control the infusion rate and at the same time to monitor the fluid level in the IV bag. This manual process leads to the interruption of the nurse's task and requires more personnel to cover all these operations. For example, an 18-month-old child died in the hospital of Liangchen, Wuxi, Jiangsu, China because of blood reflux accident occurred during the intravenous infusion [6].

Another case in New Civil Hospital, Surat wherein 14-year old boy died because of air embolism. [7] Without an access or any information on the progress and velocity of the intravenous infusion this is becoming a risk factor leading to similar medical accidents. Intravenous piggyback infusion is commonly used in medical work, and it is the pair given drug treatment technology especially to those patients who requires continuous medication. The intravenous piggyback infusion or intermittent medication is a secondary IV that fluids can cause morbidity and mortality of the patient. This piggyback infusion requires a constant manual checking and controlling of its accuracy based on the standard mathematical formula of intravenous flow rate per minute. Therefore, wireless controlling and monitoring for intravenous piggyback infusion is required. The objective of the study is to design a control system for intravenous piggyback infusion that would transmit data using wireless technology.

The specific objectives are: 1. to design a control system that can measure and control the infusion rate using wireless technology, 2. to develop an Android application that can display the infusion rate in dropsper-minute of the patient, and 3.validate the data and test the accuracy of the system using mathematical formula as mentioned in (1). Other related works discussed in Section 2, the basic principle and the structures of the proposed system are described in Section 3. The results and interpretation of data are in Section 4 . The key points are summarized, and future work was mentioned in Section 5.

\section{Related literature}

2.1Scheme for measuring and controlling the infusion rate

Several measuring equipment for intravenous drip infusion has been developed. Optical devices are commonly used to measure the drop rate [9] [10] [11] [12]. However, drop rate is not steady, the slower the drip rate, the smaller the drop size [13] therefore consistent monitoring and controlling of drip rate is very essential in infusion therapy. One of the solutions is to implement four pairs of Infrared-Light Emitting Diode (IR-LED) detectors which serve as a droplet sensor and a peristaltic pump that is connected to a microcontroller with counter timer $82 \mathrm{C} 53$ for generating pulses for the motor driving hardware based on the set drop rate [4]. However, since their system is a closed loop control system the infusion rate is set automatically. Also, it does not have a wireless monitoring capability which is very important for this kind of system. Barros and dos Santos proposed not only to monitor the drip rate but also to control the infusion rate to maintain steady and accurate infusion [9]. Cataldo et al. proposed a system which implements a Time-Domain Reflectometry (TDR) with noninvasive sensing element to automatically control and monitor the fluid level of intravenous infusion [14]. However, the measured infusion rate of their system is based on the remaining quantity of the fluid level, and it only measures the infusion rate and not the drip rate.

\subsection{Scheme for monitoring the infusion rate and remaining IV fluid}

One of the essential parts of the infusion therapy is the monitoring of the infusion rate and the fluid level. Huang and Lin proposed a warning system using Radio Frequency Identification (RFID) to detect an empty bag [15]. Krishnananda et al. used Global System for Mobile (GSM) and Liquid Crystal Display (LCD) for their monitoring purposes, which do not have a server PC that records the previous data for future data report and not capable of controlling the drip rate [16].

The intravenous infusion monitoring system based on WSN implements a ZigBee communication device which is connected to a PC that has application software that monitors the drop rate [6]. Yang and Lihua Sun also used Zigbee as a wireless sensor device and adopted the use of STM32F103VBT6 chip as microcontroller unit of the system [17].

ZigBee is low-cost, but it is not recommended for the proposed system which requires much greater distance. Also, their system does not have a monitoring device that is handy in which nurses or medical practitioners or any member of the family can carry to monitor the infusion rate of the patient.

\section{Basic principle and system structure \\ 3.1Scheme for monitoring the Infusion Rate and Remaining IV fluid}


The proposed study uses two IV bags for piggyback setup. As shown in Figure 1, the IV bag1 serves as the primary IV and the IV bag2 will serve as the secondary IV. Each IV setup has an IR sensor

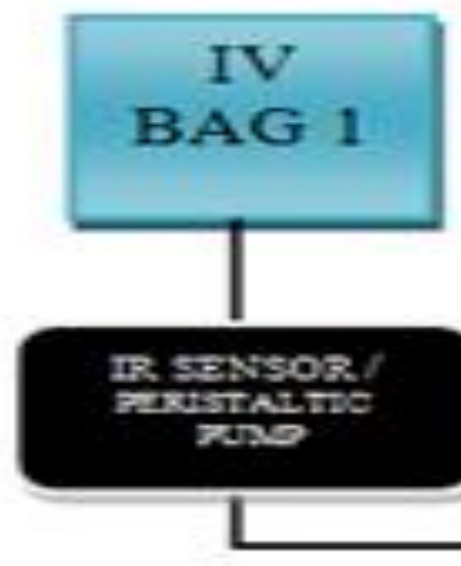

attached to each drip chamber to detect the drop per minute. The system also uses a peristaltic pump that is installed to IV tube to control the flow of the fluid.

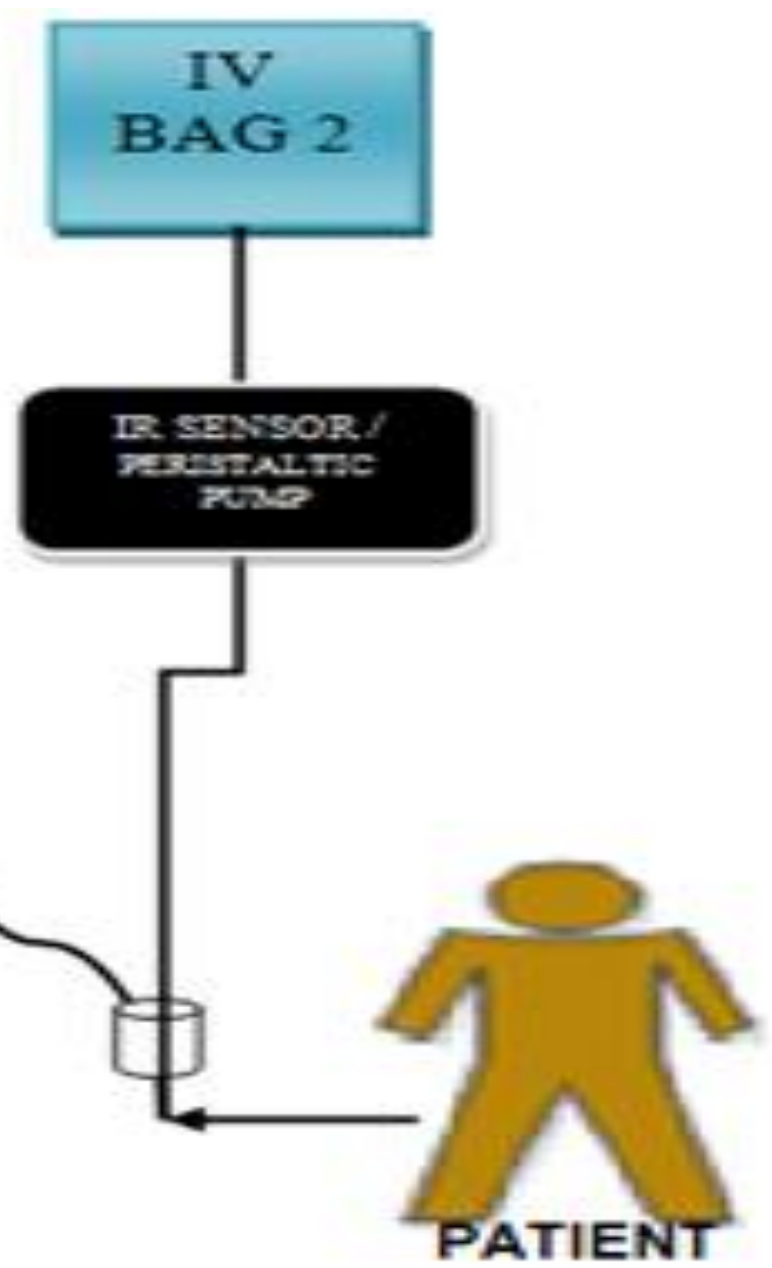

Figure 1 Intravenous piggyback (IVPB) infusion setup

The intravenous piggyback infusion system considers three parameters for the effective usage of the system for both primary (PS) and secondary (SS) setup: volume, infusion time and drop-factor. As shown in Figure 2, the user is required to $\log$ into the system and input the fluid volume (PS_fluidVol and SS_fluidVol) that will be administered to the patient, the time of infusion (PS_InTime and SS_InTime) and the drop factor (PS_drpFact and SS_drpFact). The piggyback infusion can hold $50-250 \mathrm{~mL}$ of fluid containing dissolved medication and usually requires 20-60 minutes to infuse [8]. But giving infusion treatment should be based on the condition of the patient [18]. According to Dr.Dimaano, that mild dengue cases consume 2 to 3 liters of intravenous fluid per day, but for a $100 \mathrm{~kg}$ healthy adult should get 3.5 to 5 liters per day [5].

Most of the common IV fluids available are $100 \mathrm{~mL}$, $250 \mathrm{~mL}, 500 \mathrm{~mL}$, and $1000 \mathrm{~mL}$. This system only considered $1000 \mathrm{~mL}$ and $500 \mathrm{~mL}$ volumes of fluid for 2-hour, 4-hour and 6-hour infusion time respectively for both primary and secondary IV setup for testing purposes since it only focuses on the monitoring of the drip rate. The proposed study considered a drop factor of $10,15,20$ and 60 drops per millilitre ( $\mathrm{gtt} / \mathrm{mL}$ ) for macrodrip tubing set intended for adult patients. And drop factor of 60 drop per $\mathrm{ml}$ (gtt/mL) for microdrip tubing set intended for pediatric patients [20][21]. 


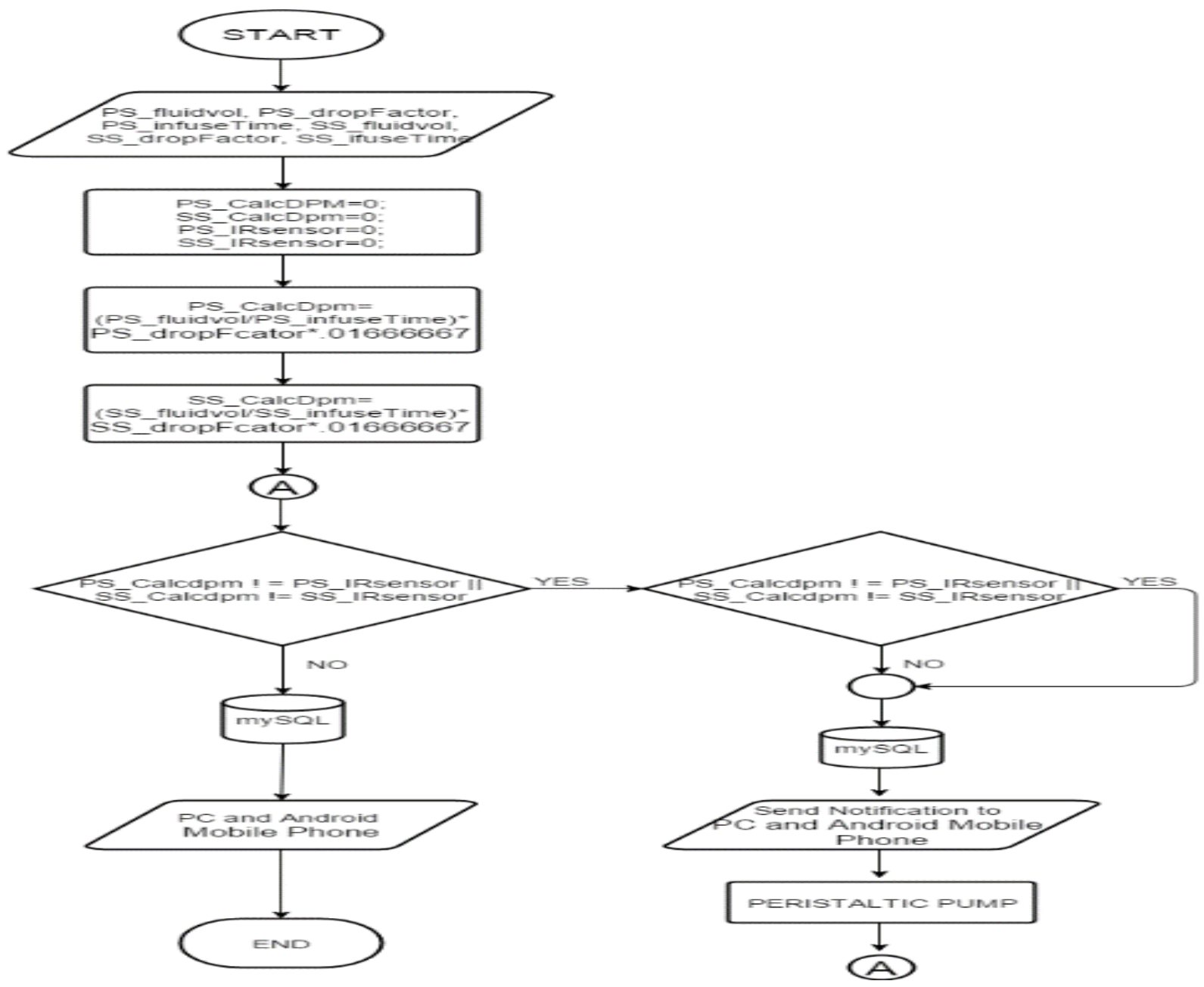

Figure 2 System Diagram of Monitoring and Controlling of Intravenous Piggyback Infusion for Primary Setup (PS) and Secondary Setup (SS)

Table 1 IVPB System parameters for primary setup (PS)

\begin{tabular}{cccc}
\hline $\begin{array}{c}\text { Iv } \\
\text { Volume } \\
(\mathbf{M l})\end{array}$ & $\begin{array}{c}\text { Drop } \\
\text { Factor } \\
\text { (Gtt/MI) }\end{array}$ & $\begin{array}{c}\text { Infusion } \\
\text { Time } \\
(\mathbf{H r})\end{array}$ & $\begin{array}{c}\text { Drop Per } \\
\text { Minute } \\
\text { (Dpm) }\end{array}$ \\
\hline 1000 & 10 & 2 & 83 \\
& & 4 & 42 \\
& 15 & 6 & 28 \\
& & 2 & 125 \\
& & 4 & 63 \\
& 20 & 2 & 42 \\
& & 4 & 167 \\
& & 6 & 83 \\
& 60 & 2 & 56 \\
& & 4 & 500 \\
& & 6 & 250 \\
& & & 167 \\
\hline
\end{tabular}

The measured drop per minute displayed on the PC and Android Mobile Phone. The PC has a Graphic User Interface (GUI) that is located in the nurse station wherein the GUI contains the measured drop per minute for both primary and secondary setup (PS_CalcDpm and SS_CalcDpm). Both setups are based on the mathematical formula (1) and the actual measurement of the prototype (PS_IRsensor and SS_IRsensor). Once the actual reading (PS_IRsensor and SS_IRsensor) of the drop rate per minute becomes unequal to the computed drop rate (PS_CalcDpm and SS_CalcDpm), it will send a notification to the PC and Android mobile for immediate assistance. It also sends a notification to PC and Android mobile phone once the infusion time (PS-InTime and SS_InTime) reaches less than 5 minutes. The parameters are listed in Table 1 and 
Table 2 which used as a guide in testing the study based on mathematical formula (1).

The PC has a control function which can turn $\mathrm{ON}$ or OFF the peristaltic pump that is wirelessly connected. The peristaltic pump squeezes the IV tube to stop the infusion whenever there is an irregularity. This happens when the drop rate gets faster or slower or when the infusion time (PS_InTime and SS_InTime) is about to finish and need a replacement of the IV bag for the patients who require continuous medication. The Android mobile phone has an Android application installed which is capable of monitoring the infusion rate in real time through $\mathrm{Wi}$ Fi connection.

Table 2 IVPB System parameters for secondary setup (PS)

\begin{tabular}{llll}
\hline $\begin{array}{l}\text { Iv } \begin{array}{l}\text { Volume } \\
\text { (MI) }\end{array} \\
500\end{array}$ & $\begin{array}{l}\text { Drop Factor } \\
\text { (Gtt/MI) }\end{array}$ & $\begin{array}{l}\text { Infusion } \\
\text { Time }(\mathbf{H r})\end{array}$ & $\begin{array}{l}\text { Drop Per } \\
\text { Minute } \\
\text { (Dpm) }\end{array}$ \\
\hline \multirow{2}{*}{10} & 2 & 42 \\
& & 4 & 21 \\
& 15 & 6 & 14 \\
& & 2 & 63 \\
& & 4 & 31 \\
& 20 & 6 & 21 \\
& & 2 & 83 \\
& & 4 & 42 \\
& 60 & 6 & 28 \\
& & 2 & 250 \\
& & 4 & 125 \\
& & 6 & 83 \\
\hline
\end{tabular}

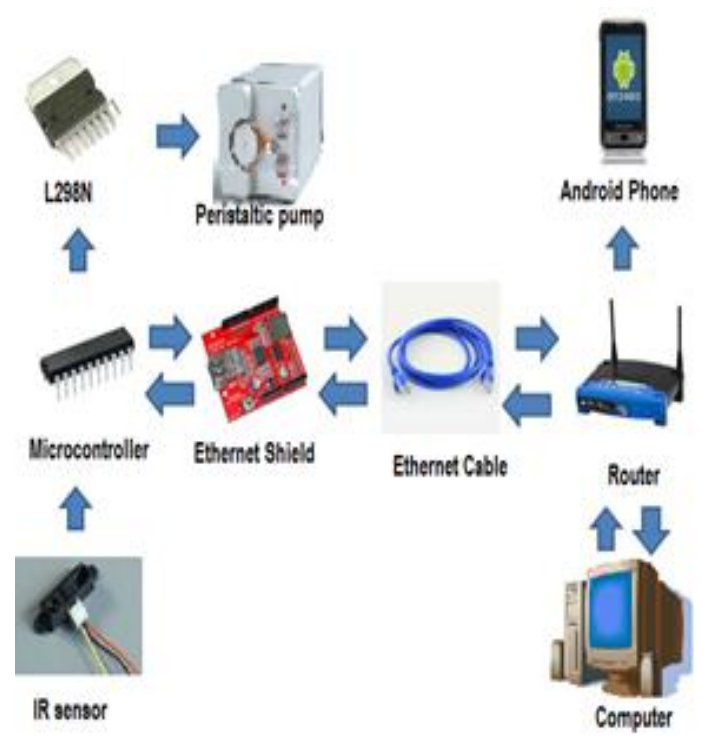

Figure 3 Intravenous piggyback infusion system architecture

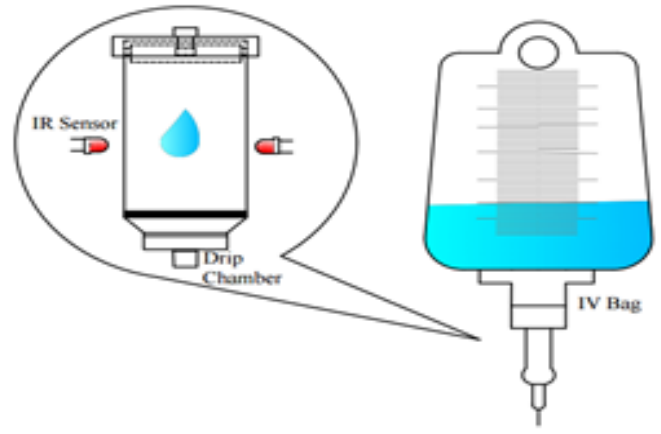

Figure 4 IVPB system drops counter setup

\subsection{System structure}

The illustrative diagram of the IVPB system is shown in Figure 3. The IR sensor detects the drop rate and is connected on ATMEGA328 that serves as the microcontroller. The ATMEGA328 sends data to Ethernet shield which is connected through Local Area Network (LAN) cable to the router. The router is connected wirelessly to the Android mobile phone and PC for monitoring and controlling purposes. If the measured drop rate and calculated drop rate are not equal, it sends a notification to the PC and Android mobile phone. Using PC, the nurse attendant assigned to the nurse station control the peristaltic pump to stop the infusion. The peristaltic pump has a DC motor which rotates according to the level of voltage generated by the motor driver.

Figure 4 shows the intravenous set up wherein the Infrared (IR) sensor is placed in the drip chamber. The IR sensor contains IR emitter, which emits light and an IR photodiode which detects light of the same wavelength. The system uses ITR9909 as IR sensor; that contains an infrared emitting diode and an NPN silicon phototransistor. The phototransistor does not receive radiation from IR LED, but when an object comes closer; the phototransistor will reflect and receive the radiation [19]. As shown in Figure 4, the ITR9909 is placed side-by-side in the drip chamber, when a droplet blocks the light emitted by the IR LED, the phototransistor receives the radiation reflected from the object.

\section{Results and discussions}

The intravenous piggyback infusion system was designed as previously described. The PC application and Android mobile application software utilized PHP and JAVA programming languages respectively. Figure 5 shows the Graphic User Interface of the IVPB system which contains the patient's number, patient's bed number, required fluid volume, drop factor and infusion time. 


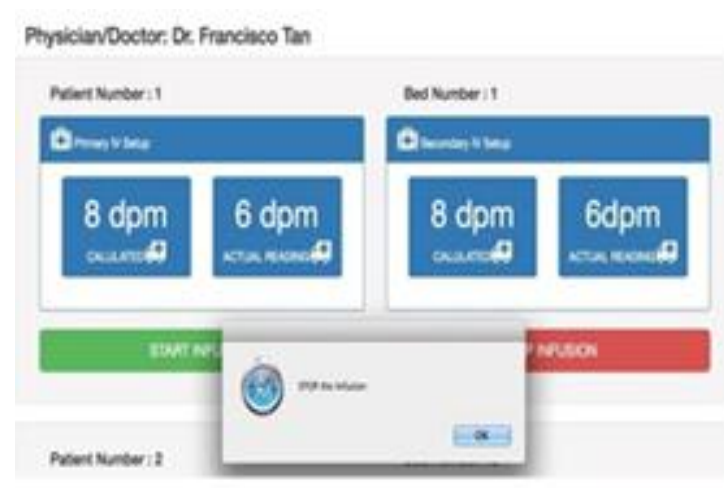

Figure 5 Graphic user interface of IVPB system

The GUI has two monitoring setups, the primary IV setup, and secondary IV. Both setups have a CALCULATED window which displays the computed drop per minute from the user input and ACTUAL READING window displays the actual measurement from IR sensor. If the actual reading is not equal to the calculated reading, the system will display a notification on the PC and Android mobile phone to control the peristaltic pump wirelessly and temporarily stop the infusion. Figure 6 shows the mobile application developed using JAVA programming language. The Android mobile application is capable of monitoring the infusion rate and viewing the notification once the Calcdpm is not equal to IRsensor of PS or SS setup.

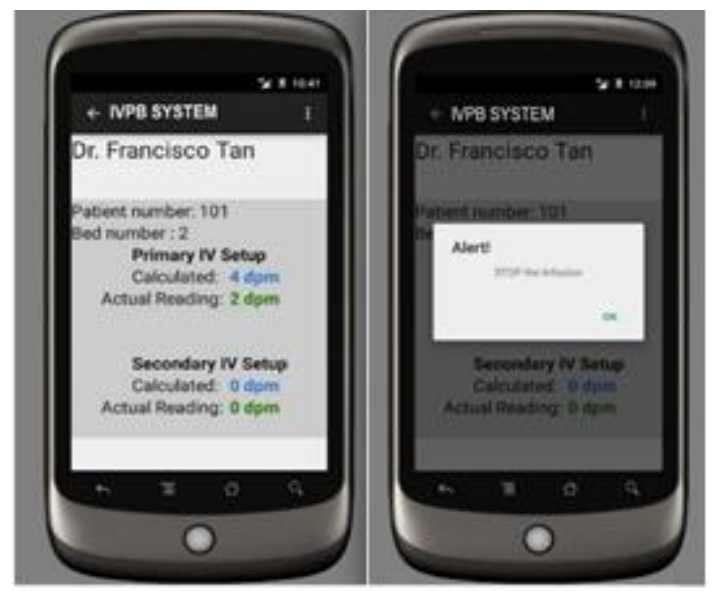

Figure 6 Android mobile application for IVPB system

In testing the accuracy of the IVPB system, the three parameters are essentials for both PS and SS setups. Both setups considered the fluid volume of $1000 \mathrm{~mL}$ and $500 \mathrm{~mL}$, drop factor of $10,15,20$ and $60 \mathrm{dpm}$ respectively and an infusion time of 2, 4 and 6 hours which are not being correlated to each other. Each testing is computed using mean average formula (2) and percentage error (3). [22][23][24]

$$
\begin{aligned}
& \bar{x}=\frac{\sum x}{n} \\
& \delta x=\frac{\text { Expected Value-Actual Value }}{\text { Expected Value }}
\end{aligned}
$$

Figure 7 shows the test result of intravenous piggyback infusion system using 1000 millilitre for 10, 15, 20 and 60 drop factor. Each drop factor was tested for 2, 4 and 6 hours. For drop factor of $10 \mathrm{gtt} / \mathrm{mL}$ with the infusion time of 2, 4 and 6 hours, the mean average is $84,41.25$ and 27 respectively and with the percentage error of $1.20 \%, 1.79 \%$, and $3.57 \%$ respectively. For drop factor of $15 \mathrm{gtt} / \mathrm{ml}$ with an infusion time of 2, 4 and 6 hours, the mean average is $123.25,63.75$ and 42.25 respectively and with the percentage error of $1.4 \%, 1.19 \%$, and $0.60 \%$ respectively. For drop factor of $20 \mathrm{gtt} / \mathrm{mL}$ with an infusion time of 2, 4 and 6 hours, the mean average is $164,83.25$ and 57.75 respectively and with the percentage error of $1.80 \%, 0.30 \%$, and $3.12 \%$ respectively. For drop factor of $60 \mathrm{gtt} / \mathrm{ml}$ with infusion time of 2, 4 and 6 hours, the mean average is $502.25,251.75$ and 167.25 respectively with the percentage error of $0.5 \%, 0.7 \%$, and $0.15 \%$ respectively.

The overall result showed a low percent error on detecting the drop rate per minute based on the mathematical formula in testing the infusion rate using $1000 \mathrm{~mL}$ fluid volume with a drop factor of 10 (A), 15 (B), 20 (C) and 60dpm (D).

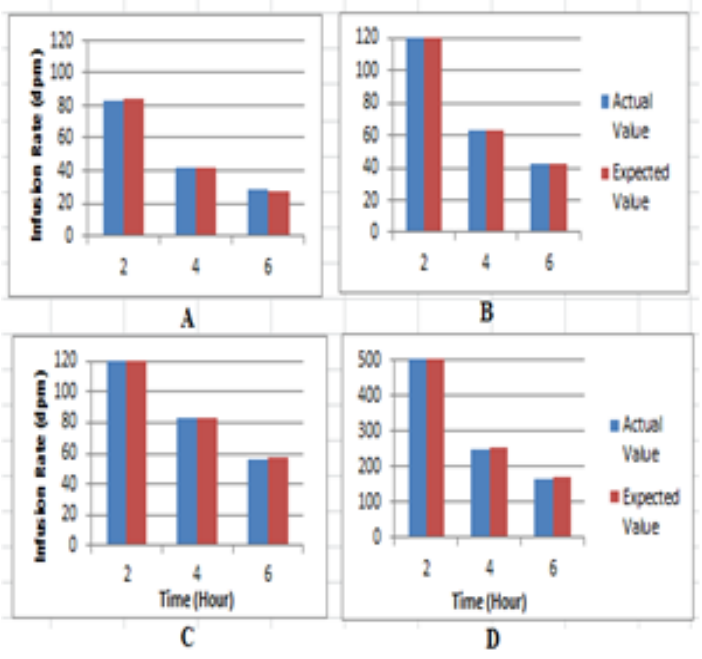

Figure 7 Test Result of IVPB system: Using 1000ml fluid volume for 2, 4 and 6 hours with drop factor of $10 \mathrm{dpm}(\mathrm{A}), 15 \mathrm{dpm}(\mathrm{B}), 20 \mathrm{dpm}$ (C) and 60dpm (D) 
Figure 8 shows the testing of intravenous piggyback infusion system using the fluid volume of 500 millilitres for 10, 15, 20 and 60 drop factor. Each drop factor is tested with an infusion time of 2, 4 and 6 hours. For test result of drop factor $10 \mathrm{gtt} / \mathrm{ml}$, the mean average is $41.5,20.75$ and 14.25 respectively with the percentage error of $1.19 \%, 1.19 \%$, and $1.78 \%$ respectively. For drop factor of $15 \mathrm{gtt} / \mathrm{ml}$ with infusion time of 2, 4 and 6 hours, the mean average is $62.25,31.25$ and 20.75 respectively with the percentage error of $1.19 \%, 0.81 \%$, and $1.19 \%$ respectively. For drop factor of $20 \mathrm{gtt} / \mathrm{ml}$ with an infusion time of 2, 4 and 6 hours, the mean average is $84,42.75$ and 27 respectively with the percentage error of $1.80 \%, 1.78 \%$, and $3.57 \%$ respectively. Lastly, for drop factor of $60 \mathrm{gtt} / \mathrm{ml}$ with an infusion time of 2, 4 and 6 hours, the mean average is 254.75 , 127.5 and 86.5 respectively with the percentage error of $1.9 \%, 2 \%$, and $4.22 \%$ respectively.

The overall result in testing the infusion rate using $500 \mathrm{~mL}$ fluid volume with the drop factor of 10 (A), 15 (B), 20 (C) and 60dpm (D) based on mathematical formula showed a minimal percentage error in detecting the drop rate. Upon conducting the testing, many tiny droplets are stocked in the wall of the drip chamber which could not be sensed by the IR sensor. Uncontrolled droplets partly affect the results of the testing. Also, the installation of IR sensor also affects the output of the testing that is why there is a minimal percentage error.

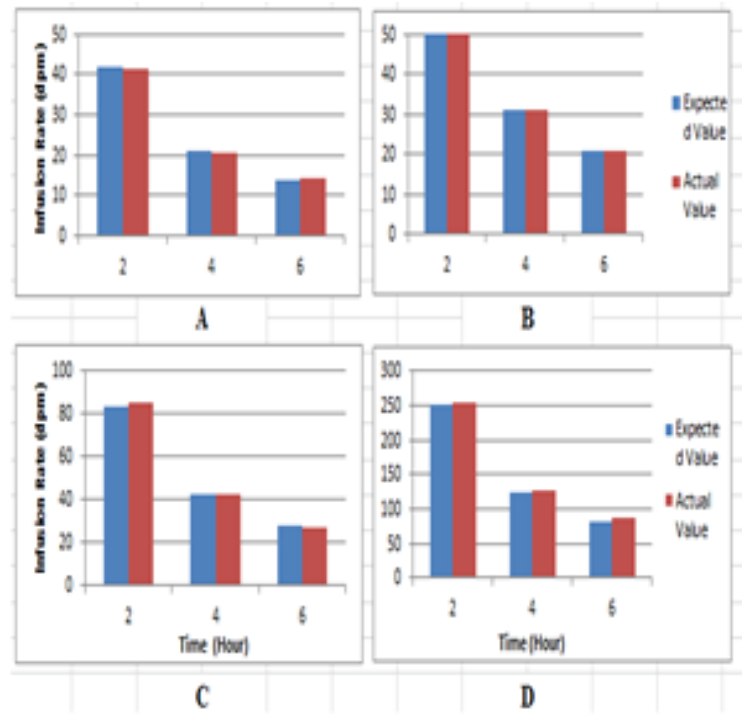

Figure 8 Test Result of IVPB system: Using $500 \mathrm{ml}$ fluid volume for 2, 4 and 6 hours with drop factor of 10dpm (A),15dpm (B), 20dpm (C) and 60dpm (D)

\section{Conclusion and future work}

Infusion therapy is one of the common medications being administered in hospitals. Therefore, real-time monitoring and controlling are highly recommended most especially for those patients who require continuous medication; this procedure is called intermittent infusion or piggyback infusion. This study can measure the infusion rate in drop per minute using IR sensor and display it on the Android mobile phone and Personal Computer using Ethernet shield as a wireless communication device. Once the actual reading and calculated reading is not equal, there is a pop-up window display on Android mobile phone and PC that alerts the attending nurse. The PC can only control the motor to stop the infusion when both readings are not equal. It also shows that the primary and secondary setup of IVPB system is successfully detected and monitored the drop rate per minute with minimal percentage error found. After a series of testing in detecting and controlling the system, it is showed that the drop rate of $10 \mathrm{dpm}$, $15 \mathrm{dpm}, 20 \mathrm{dpm}$ and $60 \mathrm{dpm}$ for both $1000 \mathrm{~mL}$ and $500 \mathrm{~mL}$ fluid volume got a $0.07 \%$ and $0.5 \%$ percentage error respectively, and it is validated using a mathematical formula. This study could not be evaluated in actual situation. Before evaluating the IVPB system in actual situations such as in hospitals, there are some changes that need to work on such as the GUI to add more functions since it will be evaluated in the hospitals, the aesthetic design of the system to attach easily to the drip chamber and realtime monitoring of the fluid level.

\section{Acknowledgment}

The author would like to acknowledge John Mark Lirac and Benedict Palermo for all the support during the system integration and evaluation and Haidee Sabile for the software design.

\section{Conflicts of interest}

The authors have no conflicts of interest to declare.

\section{References}

[1] Dougherty L, Lamb J, editors. Intravenous therapy in nursing practice. John Wiley \& Sons; 2009.

[2] Lippincott W. Fluids and Electrolytes: An Incredibly Easy! Pocket Guide. Lippincott Williams \& Wilkins; 2012.

[3] Hillman MR. The prediction of drop size from intravenous infusion controllers. Journal of Medical Engineering \& Technology. 1989; 13(3):166-76.

[4] Gupta RC, Taneja SR, Thariyan KK, Kumar S. Design and implementation of controlled drug infusion system. Journal of Scientific and Industrial Research. 2005; 64(10):761-6. 
[5] http://rp3.abs-cbnnews.com/nation/09/03/09/wrongtreatment-most-common-cause-dengue-fatality. Accessed 14 October 2014.

[6] Zhang Y, Zhang S, Ji Y, Wu G. Intravenous infusion monitoring system based on WSN. In IET international conference on wireless sensor network 2010 (pp. 38-42). IET.

[7] Agarwal SS, Kumar L, Chavali KH, Mestri SC. Fatal venous air embolism following intravenous infusion. Journal of Forensic Sciences. 2009; 54(3):682-4.

[8] Olsen JL, Giangrasso A, Shrimpton DM. Dosage calculations for nurses. Pearson Education; 2009.

[9] Barros E, des Santos MV. A safe, accurate intravenous infusion control system. Micro, IEEE. 1998; 18(5):1221.

[10] Oden M, Mirabal Y, Epstein M, Richards-Kortum R. Engaging undergraduates to solve global health challenges: a new approach based on bioengineering design. Annals of biomedical engineering. 2010; 38(9):3031-41.

[11] Kamble VV, Pandey PC, Gadgil CP, Choudhary DS. Monitoring of intravenous drip rate. Proceedings of ICBME 2001(pp. 21-4).

[12] Wen $X$. Design of medical infusion monitor and protection system based on wireless communication technology. In second international symposium on intelligent information technology application 2008 (pp. 755-9). IEEE.

[13] http://www.thinkmind.org/index.php?view=article\&ar ticleid=etelemed_2014_9_30_40071. Accessed 22 June 2015.

[14] Cataldo A, Cannazza G, Giaquinto N, Trotta A, Andria G. Microwave TDR for real-time control of intravenous drip infusions. IEEE Transactions on Instrumentation and Measurement. 2012; 61(7):186673.

[15] Huang CF, Lin JH. A warning system based on the RFID technology for running-out of injection fluid. In annual international conference of engineering in medicine and biology society, EMBC 2011 (pp. 221215). IEEE.

[16] Krishnananda , Manjunatha N, Srivastava N, Kumar $\mathrm{P}$, Pavan R. Autonomous intravenous infusion system $\&$ health monitoring. Proceedings of ASAR international conference 2014; (pp. 48-50).

[17] Yang W, Sun L. A novel medical infusion monitoring system based on ZigBee wireless sensor network. In proceedings of the 2009 international symposium on web information systems and applications (WISA'09) 2009 (pp. 291-3).

[18] Padhi S, Bullock I, Li L, Stroud M. Intravenous fluid therapy for adults in hospital: summary of NICE guidance.2013.

[19] http://www.everlight.com/file/ProductFile/ITR8102.p df. Accessed 05 November 2015.

[20] Nentwich PF. Intravenous therapy: a comprehensive application of intravenous therapy and medication administration. Jones \& Bartlett Learning; 1990.

[21] Snyder R, Schoenborn B. Medical dosage calculations for dummies: John Willey and Sons.2011.
[22] Abramowitz M, Stegun IA. Handbook of mathematical functions: with formulas, graphs, and mathematical tables. Courier Corporation; 1964.

[23] Werstiuk C. The relay testing handbook\# 2D: relay testing fundamentals. Valence Electrical Training Services LLC; 2007.

[24] Devore J. Probability and statistics for engineering and the sciences. Cengage Learning; 2015.

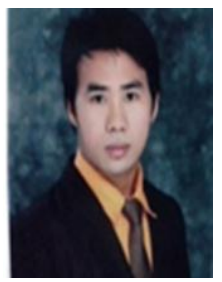

Gil R. delas Alas $\mathbf{J r}$ received his Bachelor of Science in Computer Engineering in 2007 at Technological Institute of the Philippines, Quezon City, Philippines, taking his Masters Studies in the field of Computer Engineering in the same institution. He is a fulltime faculty member of College of Computer Studies at Our Lady of Fatima University, Philippines. His research interest is related to digital designing, and software-hardware integration.

Email:gdelasalas25@gmail.com

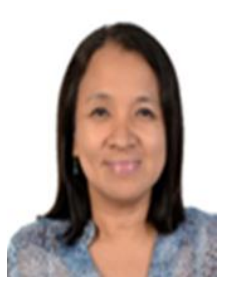

Jesusa N. Padilla holds degrees in Doctor of Technology from the Technological University of the Philippines (TUP) and Master of Engineering major in Computer Engineering from the Pamantasan ng Lungsod ng Maynila (PLM). She is currently the Dean of the College of Engineering and Architecture and graduate program faculty member of the Technological Institute of the Philippines, Quezon City. She is a Professional Electronics Engineer and an ASEAN Engineer and had experience in the electronics industry as a design engineer.

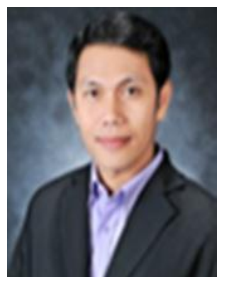

Dr. Bartolome T. Tanguilig III took his Bachelor of Science in Computer Engineering in Pamantasan ng Lungsod ng Maynila, Philippines in 1991. He finished his Master's Degree in Computer Science from De La Salle University, Manila, Philippines in 1999, and his Doctor of Philosophy in Technology Management from Technological University of the Philippines, Manila in 2003. He is currently the Assistant Vice President for Academic Affairs and concurrent Dean of the Graduate Programs of the Technological Institute of the Philippines, Quezon City. Dr. Tanguilig III is a member of the Commission on Higher Education (CHED) Technical Panel for IT Education (TPITE), the chair of the CHED Technical Committee for IT (TCIT), the founder of Junior Philippine ITE Researchers (JUPITER), Vice President - Luzon of the Philippine Society of IT Educators (PSITE), board member of the PCS Information and Computing Accreditation Board (PICAB), member of the Computing Society of the Philippines (CSP) and a program evaluator / accreditor of the Philippine Association of Colleges and Universities Commission on Accreditation (PACUCOA). 